\title{
The Economic Impact of Geopolitical Unrest on Thailand's Tourism Industry
}

\author{
Johan Van Rooyen \\ Department Business and Technology, Webster University, Webster Groves, Thailand \\ Email address: \\ rooyenjv@webster.ac.th \\ To cite this article: \\ Johan Van Rooyen. The Economic Impact of Geopolitical Unrest on Thailand's Tourism Industry. Journal of Business and Economic \\ Development. Vol. 3, No. 2, 2018, pp. 30-42. doi: 10.11648/j.jbed.20180302.11
}

Received: March 28, 2018; Accepted: May 21, 2018; Published: June 28, 2018

\begin{abstract}
The purpose of this research was to study the economic effect of a Coup de Tat on Thailand's Tourism Industry and whether there was growth thereafter. Tourism has become a critical economic sector and a major driving source of the global economy. Thailand's vibrant tourism sector has played an increasingly important role in the economy in recent years. Although the tourism sector balances the country's economic growth, it is argued that there are some negative impacts of tourism industry which affect the growth of the economy. Hence, this paper was conducted to investigate the actual positive and negative effects of tourism on the economic growth in Thailand from the perspective of general tourism. This empirical study used secondary sources. The findings from the practical study reported in the correlation table demonstrated that there is a very strong positive relationship between the number of tourist arrivals to Thailand and two of GDP's affecting factors (consumption and employment).
\end{abstract}

Keywords: Positive and Negative Impact of Tourism, Economic Growth, Tourism Industry

\section{Introduction}

The tourism industry in Thailand is one of the largest and most promising in the world. Ranking at 5th place (out of 185 countries) on growth on total contribution to GDP, needless to say it is one of the main sources of the country income and one to keep an eye on. Tourism is one of the fastest growing economic sectors, along with the positives impacts also comes the negatives ones. These impacts on the economic situation in Thailand will be identified first.

The Thai economy in 2018 is still affected by the economic situations that happened in the previous years. Due to the government's crackdown on the zero-dollar tours, Thailand risk having a decrease in Chinese tourists. Political issues are another one of the risk factors. The ongoing political struggle in Thailand, including the Yingluck Shinawatra case, is one of the main factors impacting the country's economy. Other risk factors are the US political changes, the unstable financial economy in Europe and China and also the consequences of Brexit. All of these factors may reduce the free flow of international trade and the export of products from Thailand and of course the tourism industry as well.

Regardless of the risk factors, supporting factors and incentives are contributing to a positive growth of Thai economy. The outflow from the first-car program resulted in households having increased purchasing power. The recovery of domestic household spending will result in a boost of income to not only the households but also for the exporters. It is also said to increase government spending, including cash transfer to low-income earners and the new income tax structure will boost the economy in various sectors. Along with these government measures, the investments in infrastructure of mega projects, the likely stable $1.5 \%$ policy rate on bank loans is all supporting factors. The government also has full support on the country's tourism industry by giving enormous incentives to investors, implementing on new policies and encouraging quality tourists to visit Thailand and increase the sustainable growth of the economy. $[2,4,14,15]$.

\section{Methodology}

This paper discusses the tourism industry in Thailand and its different types. Moreover it explains the relationship between the important variables closely related to the tourism industry which is the number of tourist arrivals as independent variable, and the contribution of tourism 
industry toward the gross domestic product GDP of Thailand as the dependent variable along with some factors such as employment and opportunities in the tourism industry, internal tourism consumption affecting the gross domestic product (GDP) of Thailand.

Various time-data ranged from 2012 to 2016 were collected from secondary sources, these sources allowed data analysis to be conducted.

Since GDP is such a broad area with several factors rather than only tourism industry variables, it is difficult to see the direct impact of tourism industry on economic growth. Hence, this paper attempts to use the economic theories of demand and supply supported by statistical methods to analyze the relationship between tourism and some factors affecting the GDP of Thailand during the last 5 years. [4]

\section{Types of Tourism in Thailand}

By definition, tourism is the activities of people traveling to and staying in places outside their usual environment for leisure, business or other purposes for not more than one consecutive year. The tourism sector today aims to cater to the needs and preferences of all types of tourists, and thus, seems to take into consideration specific areas of their interest. A plethora of tourism types and innumerable options are given for international travelers to choose from nowadays. However, in this report, the focus was on only 2 types of tourism in Thailand which are Leisure Tourism (including Sex, Adventure and Retirement Tourism) and Medical Tourism.

The government and private sector stakeholders in Thailand have been pro-active in marketing the merits of the Thai tourism sector around the world with a string of promotional campaigns. As a result, the travel and tourism sector has grown to become one of the country's most productive and sustainable industries, contributing a total of \$72bn towards the economy in 2014 (World Travel \& Tourism Council). [3, 11]

\subsection{Sex Tourism}

Thailand's sex industry draws millions of tourists to the country. According to a report by Safe World for Women, in 2003 , prostitution was a US\$ 4.3 billion industry, accounting for three percent $(3 \%)$ of the country's income. Although illegal, prostitution in Thailand is monitored and regulated by the government to stem the spread of STDs and to prevent excesses. Prostitution catering to foreigners is believed to be around $20 \%$ of the total prostitution scene in Thailand, and is concentrated in red-light districts of Pattaya, Patpong, and Patong as well as other tourist destinations. Data indicates that the popularity of sex tourism in Thailand is still high amongst foreigners. [15]

\subsection{Adventure Tourism}

Thailand offers a multitude of outdoor activities for adventure seekers. Especially the North Western part of
Thailand, Chiang Mai and its surroundings are any adventure enthusiast's playground with a huge array of activities on offer; from outstanding mountain biking and trekking to rafting and elephant riding. If Chiang Mai and the North are associated with adventure, culture and family friendly activities, then the South is loved for its beaches and sunshine. In the heartland of Thailand, one will have the opportunity to trek, explore lost kingdoms, ride elephants, walk with tigers, rafting and even stay with hill tribe people. The trend of this type of tourism is slowing in growth the past few years due to countries like Cambodia and Myanmar which are becoming easier accessible. $[2,10]$

\subsection{Retirement Tourism}

Retirement tourism is the potential of tourism for elderly travelers. The concept of retirement tourism is in the form of cottages for rent to elderly tourists. The cottage itself must meet several requirements including strategic location and a clean, beautiful comfortable environment, and equipped with facilities such as hospitals filled by competent medical personnel. It is expected that those who live there can spend their old age in a relaxed atmosphere, filled with fun activities for the elderly, such as gardening, arts or just socializing. Thailand is one of the top retirement destinations in Southeast Asia because it is a mix of low pricing, affordable health care, good food, and foreigner-friendly destinations. Thousands of foreigners have settled in this country in world-renowned resorts such as Koh Samui, Koh Lanta and Phuket and cities including Bangkok, Pattaya, Chiang Mai and Chiang Rai, and in the smaller towns of Hua Hin, Cha-am and Pai. [13]

\subsection{Medical Tourism}

Medical tourism constitutes the travel of patients from one place to the other in order to acquire proper medical care and treatment. Common treatments that patients indulging in medical tourism seek include treatments for certain genetic disorders and specialized surgeries such as joint replacement, cosmetic surgeries, psychiatric and alternative healing treatments. Medical tourism is a large and growing sector within Thailand's extensive tourism and healthcare industries. The country is attractive to potential medical tourists and international patients for a number of important

reasons. Thailand was the first Asian country to achieve Joint Commission International (JCI) accreditation in 2002. Many hospitals have experienced often Western-trained, medical professionals and the latest medical technology with significantly lower costs of treatment when compared to corresponding procedures in western countries. Some of the primary destinations for medical tourism in Thailand are Bangkok, Chiang Mai, Hua Hin, Ko Samui, Pattaya, Chonburi, and Phuket. Foreigners seeking treatment have made Thailand's private hospitals the world's leading destination for medical tourism, attracting an estimated 2.81 million patients in 2015, up 10.2 percent from the previous year. $[5,8]$ 


\section{Porter's Five Forces Framework}

According to Harvard professor Michael Porter, the five industry forces determine an industry's overall attractiveness and potential for long-term profitability. In conducting the research, the analysis is structured according to each of the five forces of Porter's model, the "Porter's 5 forces analysis"; power of suppliers, power of buyers, industry rivalry, substitutes and complements and the threats of new entrants.

\subsection{Power of Suppliers}

The supplier power in Thailand's Tourism Industry is considered to be low to moderate. The suppliers for the tourism industry include airlines, hotels, travel agents and other transportation services such as tour bus companies. There is an increasing flight frequency of low-cost carriers both domestic as well as inbound to the country. They provide low-fare options to travelers which attracts more tourists coming in the country. Besides, the travel agents and tour operators are using different pricing strategies for more inbound tourists with a variety of tour packages. There are major chain-hotels and key local hotel brands, but the bargaining power is reduced because of the similar premium quality of services and the hotels have to attract their fragmented customers. Thailand government doesn't restrict the industry suppliers with certain regulations, yet encourages higher spending and quality tourists to maintain the sustainability of the industry. [3]

\subsection{Power of Consumers}

For all kinds of Tourism in Thailand, customers have high bargaining power. The industry's significant growth and the tourists are more capable of making use of the technological advancements as the mean of communication such as the internet, where they can go online and survey the best hotel, travel agent or airline that offers great services which in turn increase their bargaining power. The freedom buyer has in this industry reduced the switching cost and the suppliers must try their best to attract the customers and get their loyalty with a very unique and valuable differentiator. For some out of season periods, the hotels offer discounts and incentives to reduce the bargaining power of buyers. Certain healthcare institutes also offer seasonal and occasional discounts for medical checkups such as Mother's Day special or skin whitening package promotion in summer at dermatological centers. [5]

\subsection{Threat of New Entrants}

The industry exhibits high entry barriers restricting new entrants, particularly because of the combined factors of economies of scale and high capital cost of entry, together with the limited supply of suitable locations. Thailand has a well-developed hotel industry. Major chain hotels such as Marriott, Hilton, Accor, etc. are taking the strong positions in the market whereas the domestic hotel groups such as Centara Hotels and Resorts, Dusit International and Minor
International are also considered to be key players in the industry. The Hotel Industry on a global basis is characterized by high capital costs and a high proportion of fixed costs to total costs. Hence, strong growth rates in the country's tourism industry have resulted in major investments in its hotel industry, particularly in the high end market. New firms coming to this industry will have a hard time trying to get a place in the market by competing against these major players. In addition to the hotel industry, Thailand's affordable medical treatments attract medical institutes and technology firms investing in the country. The same as the hotel industry, the healthcare sectors huge capital requirements are the biggest barrier because of the government regulations like buying property, patents (heavy government policy protection barrier); and initial cash investment of establishing supply chain networks requires huge amounts of money. These barriers reduce the rate of entry for new firms, thus maintaining a level of profits for those already in the industry. A report produced by Thailand Authority of Tourism stated that more than $43 \%$ of patients from Asia are coming to Thailand for treatment. The government is also carrying out a strategic plan for Thailand to be the medical hub of the region. Thus, the market growth in the next few years will be driven by demand for upgrades and expansion of existing health care facilities and medical devices, as well as replacement of accessories. Leading private hospitals have been investing to reinforce their position in the market. [8]

\subsection{Substitutes}

Thailand is taking a strong position in Top Asian Tourist Destinations and the customers' loyalty towards this industry is dominated by substitutes. The prestige hotels with unique services, the outstanding natural and cultural experiences at lower than normal prices and one of the best medical treatments offering in the country is differentiating the country with its substitutes. Here the substitutes for Thai tourism industry are the neighboring countries, namely Cambodia, Indonesia, Malaysia, Singapore and Vietnam. MasterCard 2017 Tourist Destinations shows that Bangkok is the most visited city in Asia-Pacific region attracting more than 19 million overnight visitors in 2016 followed by Malaysia and Singapore from SEA countries. Long term (2017-2027) growth rate contributing to GDP, the ranking is still favorable for Thailand though others neighboring are closing in respectively. [15]

\subsection{Complements}

Complements can be considered as the six forces of competition and the Tourism industry and the airline industry has the best complement products. When a traveler heads to a tourist destination, he or she often gets there by airplane. Similarly, whenever a consumer travels on an airplane, that consumer is most likely going to visit a destination which is a part of the Tourism industry, such as a hotel or a medical center. A number of strong prestigious national carriers such 
as Bangkok Airways, Nok Air and Thai Lion bring visitors from all around the world to Thailand at budget fares that increase the number of arrivals also raises the demand of services from budget airlines by price-sensitive customers.

\subsection{Industry Rivalry}

The internal rivalry in Thailand Tourism Industry is considered to be moderate as the key players in the industry offer the same services. For example, Chiang Mai is positioned as the best retirement destination for foreign elderly because of its healthy lifestyle, affordable healthcare and living expenses located in the beautiful natural countryside. Hence, tour operators and medical institutes tailor their products based on the traveler's preferences and choice in this particular area. The way tourism products are integrated and developed in this area and in metro cities with key tourist destinations places, private hospitals and hoteliers are almost the same. This makes the industry competition healthy and all players are helping to increase the industry growth.

\subsection{The Five Forces Framework of Thailand Tourism Industry}

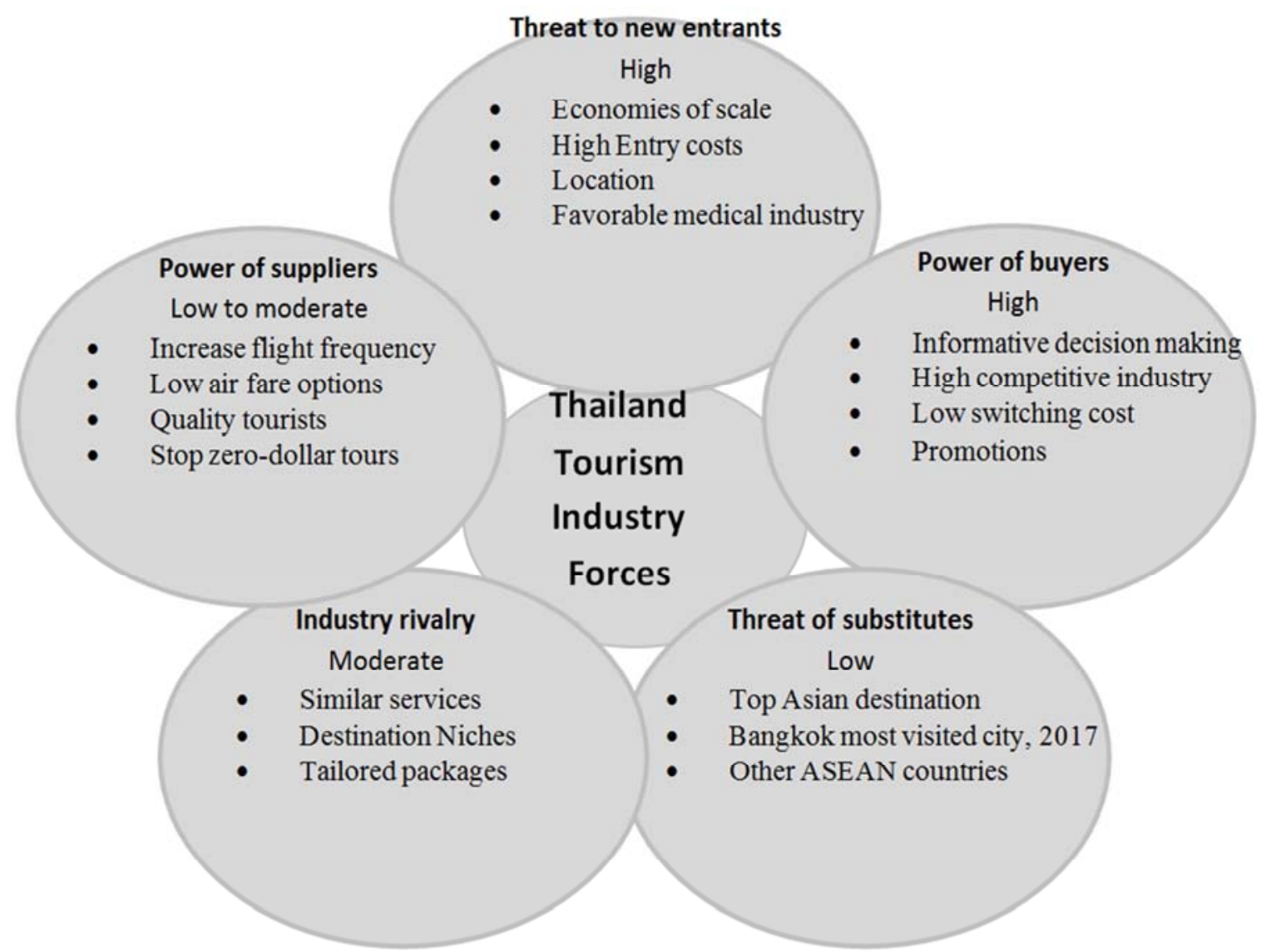

Figure 1. Threats to new entrants.

\subsection{Incentives}

Thailand government is attempting to improve the tourism industry with certain incentive schemes. Since October 2016, the government is encouraging to crack down "Zero- Dollar Tours" in order to maintain 'sustainable growth' in the tourism sector. According to The Tourism Authority of Thailand (TAT), the shift of focus by the Thai government to attract more 'quality' tourists and the policy to end zerodollar tours from China will support the revenue numbers forecasted for 2017. In improving the industry, the government is working on TAT's 2018 master plan "Thailand 4.0 " with the purpose of generating revenue and increase visitor arrivals; promote new ideas as well as Inclusive Tourism that maintains a balance between the economy, society and the environment. The plan will be implemented, starting October 2017 for a period of 12 months and customers are segmented into different niches starting from first-timers to repeaters, senior citizens to sports enthusiasts. In order to increase the revenue made from international travelers, the government introduced tourist visa incentives such as visa waiver to tourists from 21 countries and visa reduction schemes. These incentives make Thailand an attractive country for both long term tourism and short-term visits and invite more visitors to enjoy the country's amazing experiences as its 20-year marketing slogan of "Amazing Thailand". Under the 2018 plan, the government also developed a new concept "Open to the New Shades of Thailand" which aim to deepen the unique Thai local experience, growing the business of the tourism industry's 
major key players and upgrade the country's image as a land of amazing diversity into a million shades. In addition to tourist visa incentives, Thailand's Immigration Bureau has approved Thailand Ten-Year Retirement Visa, officially called O-A Long Stay Visa to 14 nationalities. Since the number of foreigners looking to stay and retire in Thailand is on the rise, especially in main areas of popularity like Chiang Mai, Bangkok, Chon Buri, and other popular resorts close to the seaside, the government plans to capitalize on this increase of wealthy foreigners staying in Thailand by raising the industry's revenue. In terms of incentives in medical tourism sector for elder generation and international patients, the government has a 10 year strategic plan from 2016 to 2025 , by giving investment incentives to medical companies and investors as a mean to transform. Thailand received 30 million tourists in 2015, of which about 16 million, or 53 percent, came for medical and wellness treatments. Tourists who specifically sought medical treatments came in at a 25 percent increase over the previous year, and the rest - about 15 million - came for wellness tourism, a 38 percent increase from 2014, according to the latest data from TAT. Also, the research based on Kasikorn Research Centre estimates that income from international patients at private hospitals will generate THB48 to THB49 billion year-on-year, an increase of $3 \%$ to $4 \%$ year-on-year. Hence, with the government's assistance and incentive schemes, this sector has attracted rising investment and with $\mathrm{R} \& \mathrm{D}$ innovations, medical device investors are accelerating the current medical technology and transitioning the country into medical hub of the region in the near future. Hence, Thailand tourism is growing in a longterm promise with extra government support and incentives. $[7,9,14,15]$

\section{Impact of Tourism}

\subsection{Positive}

More tourists mean more people and because more people coming to the country, the infrastructure, leisure facilities and local facilities will improve. The improvement to these things will result in better roads, electricity, better water and sewage systems and improved public transportation networks. This will not only benefit tourists, but also local citizens, increasing the overall socioeconomic culture.

The locals will interact with tourists and thereby learn about other cultures than their own, which will expand their knowledge of the world.

The government will try to improve the aesthetic view of the country, which means more plants and trees. This will help the ecological balance of the country, and especially in Asia, where smog is a big problem.

There are of course also many economic impacts of tourism, and the first one is the GDP growth rate. The graph shows the GDP growth rate of Thailand over the last five years. $[9,11]$.

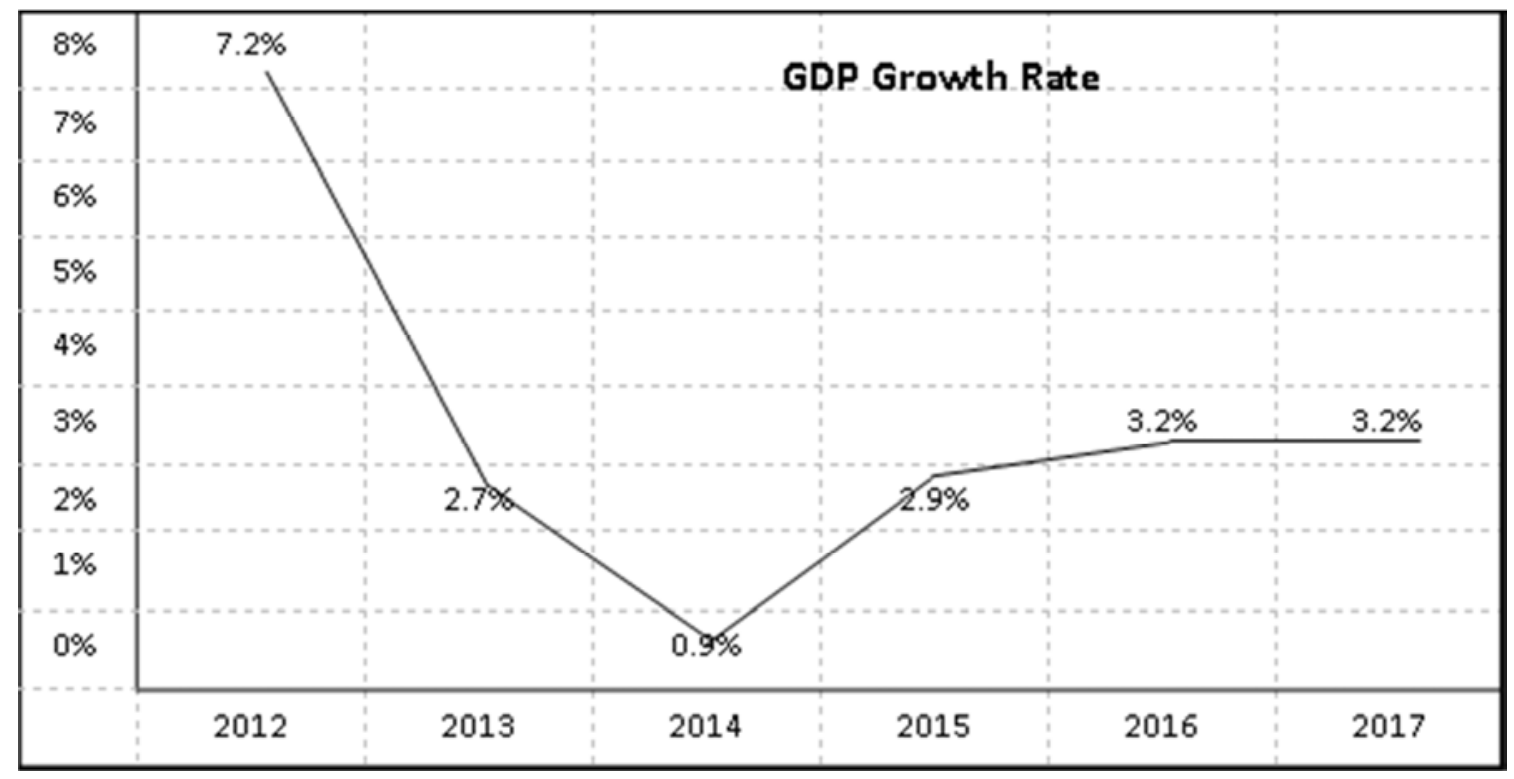

Figure 2. GDP Growth Rate.

The growth rate from 2017 is from the first 6 months of the year, which indicate that there could be a continuing growth which has also been seen in the last few years. The drop in 2014 in many of the graphs can be explained as the anti-government demonstrations in late-2013 till mid-2014.
The next graph shows the total contribution to GDP, meaning the economic activity from hotels, travel agencies, airlines, investments and supply chains connected to travel and tourism. [15] 


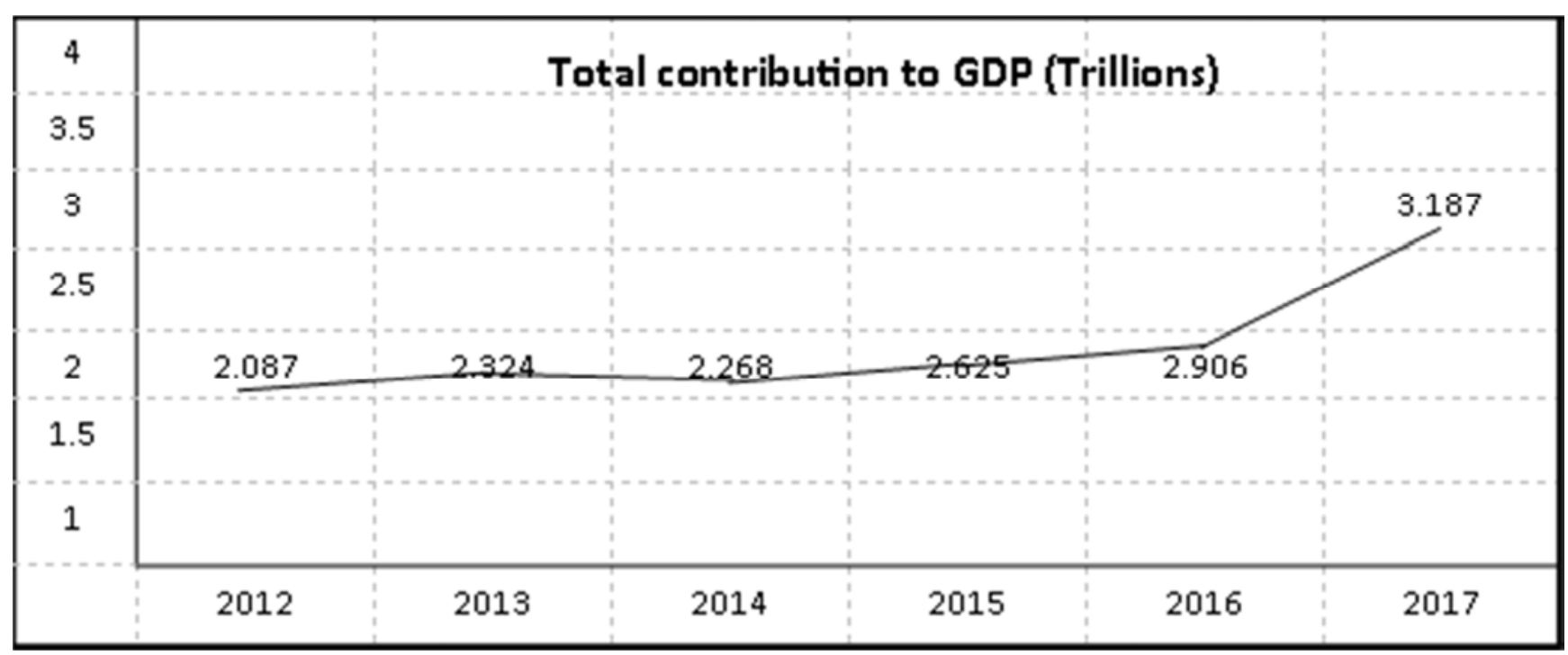

Figure 3. Total contributions to GDP.

The number increases, meaning that tourists spend more money during their travel period and thereby, the Tourism industry contributes to better economic conditions. In 2016, the total contribution stood at $20.6 \%$ of the total GDP and it is estimated that it will stand for $31.7 \%$ by 2027 .

In 2015, every tourist spent an average of 5,142 baht per day. Depending on where the tourists come from, they spend different amounts of money. [15]

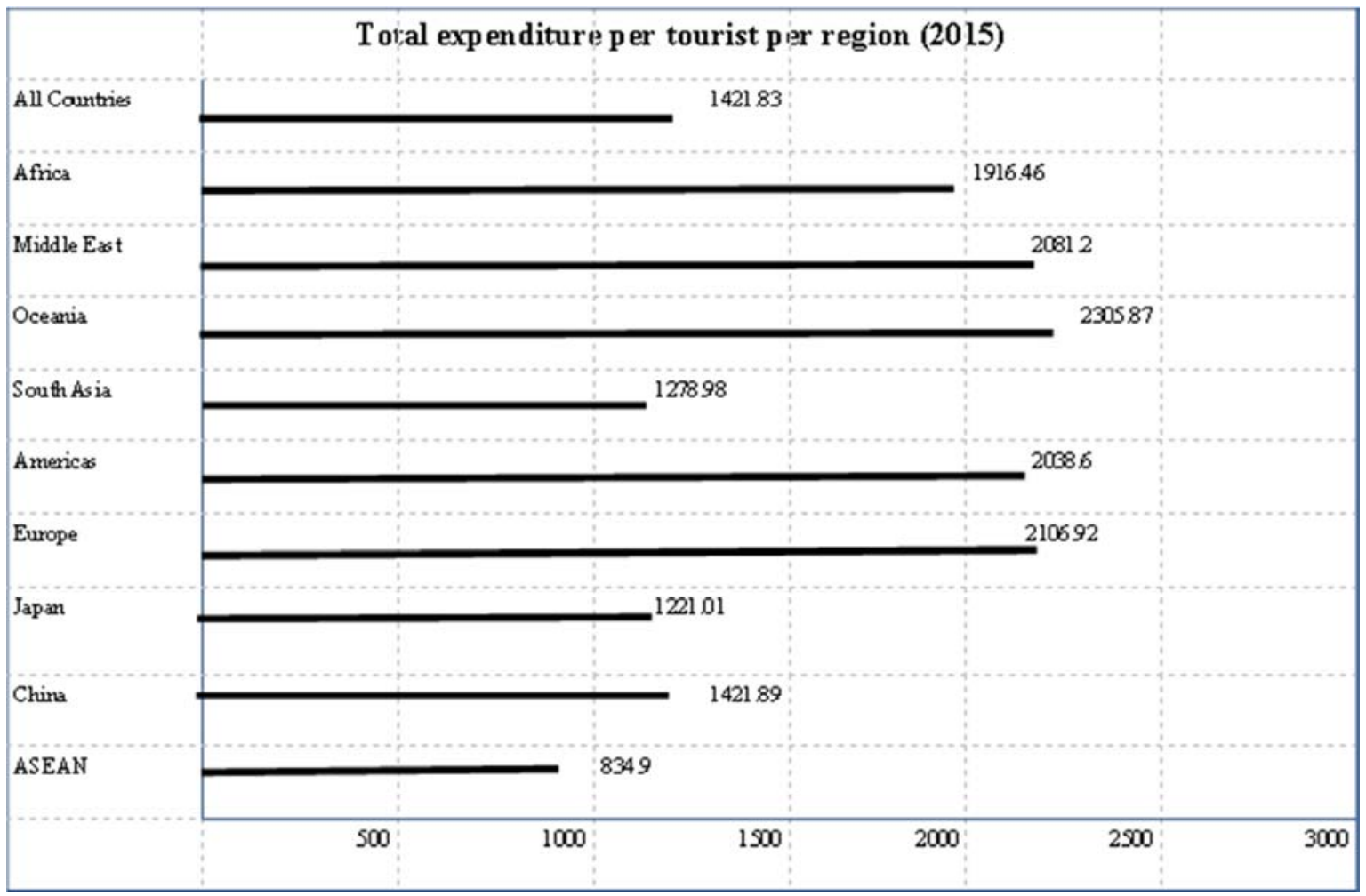

Figure 4. Total expenditure per tourist per region 2015.

The graph shows the total expenditure per tourist per region from 2015. The numbers are based on the average length and vacation and the average amount of money spend per tourist per region. Tourists from Asia have shorter vacations than tourists from Europe and USA. The amount is in US dollars and includes all the money spent while being in the country. The European, American and Australian tourists tend to stay longer because it is a longer trip to get to Thailand and therefore they spend more money per tourist than the Asian tourists.

The employment is also affected by tourism, because more tourists often mean more work for the locals. [11] 


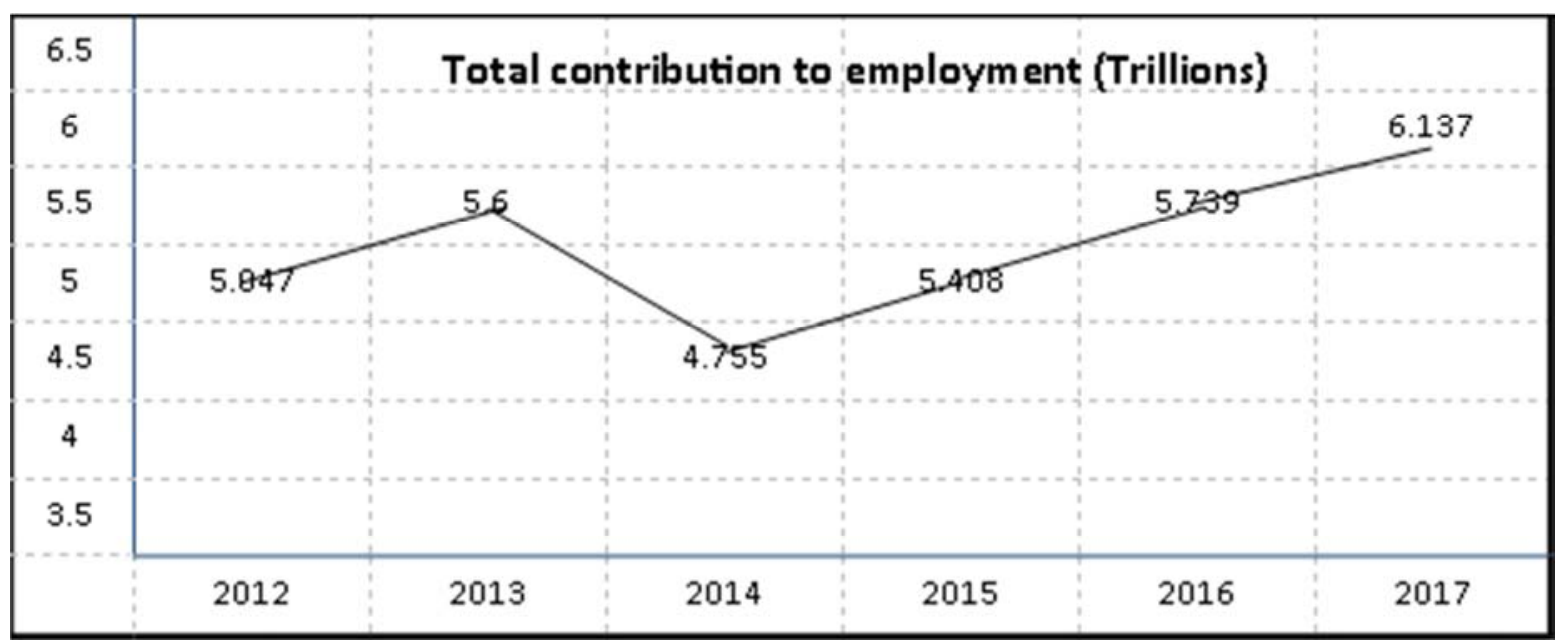

Figure 5. Total contribution to employment.

The graph shows the total contribution to employment. There is both direct and indirect contribution. The direct contribution is the employment by hotels, travel agencies and airlines. The indirect contribution is the employment from investments and supply chains. In 2016, the direct contribution was $2,313,500$ jobs. In 2015, the total contribution stood for $15,1 \%$ of the total employment. There has been an increase over the last three years, which continue from 2017 forward. [4]

The total number of tourists arriving in Thailand has increased over that last few years.

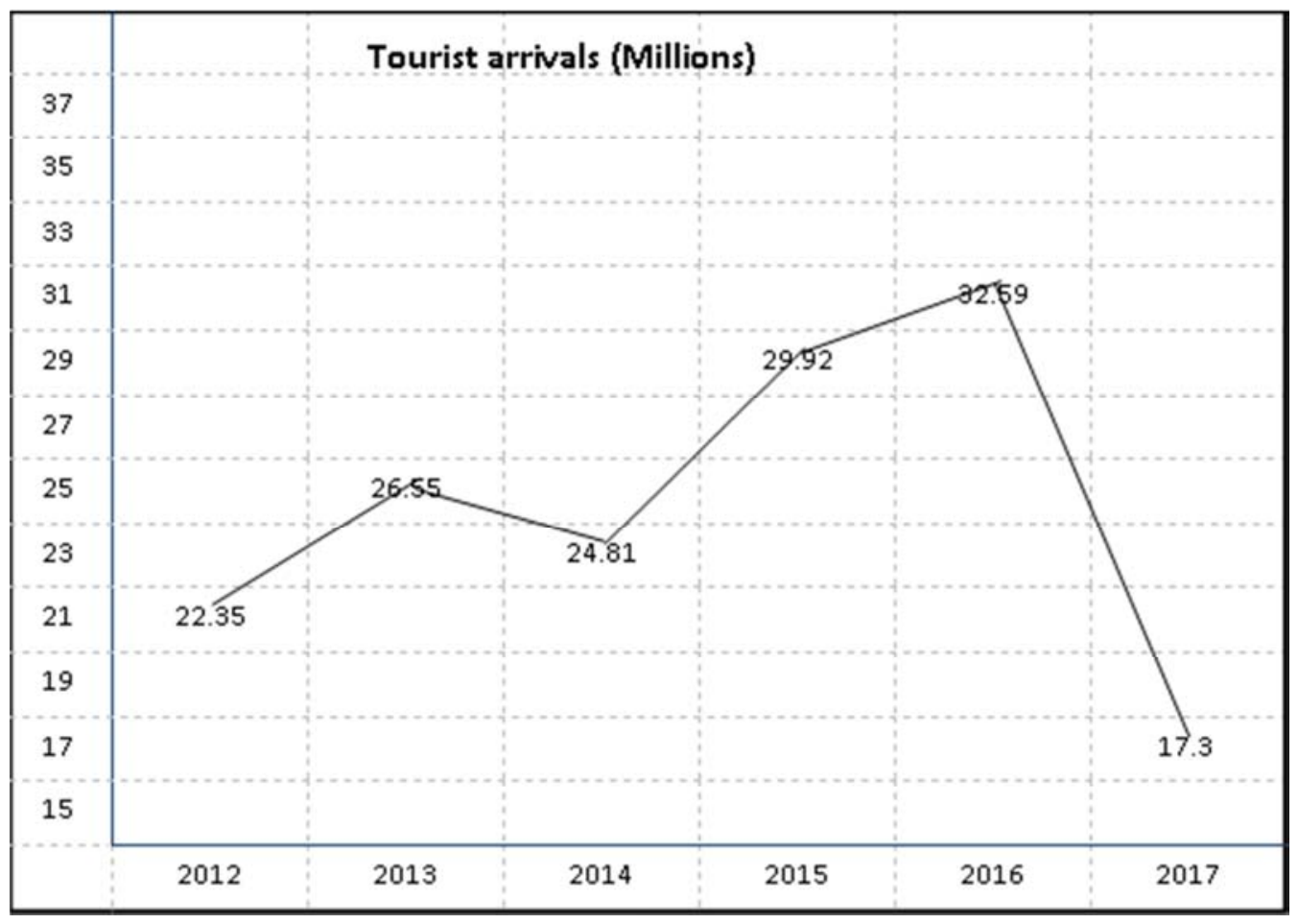

Figure 6. Tourist arrivals.

As mentioned before, there were anti-government demonstrations during 2013-2014 which lead to a decrease in the number of tourists arriving in Thailand. As seen on the graph, there has been an increase during the last three years and it is estimated that this increase will continue in the future.

During the first six months of 2017, tourist arrivals was 17,3 million and it is estimated that the total number of arrivals will end at 37 million by the end of the year.

Normally, arrivals are only affected over a period of 2-3 months whenever setbacks happen and then they increase again [15]

Seeing that Thailand has an off-on season, the total number of arrivals will depend on when the setbacks occur. The table shows the quarterly arrivals, where the increase and decrease depending on the season is visible. 
Table 1. Quarterly arrivals.

Quarterly arrivals (Millions)

\begin{tabular}{lllll}
\hline & January - March & April - June & July - September & Oct. - December \\
\hline 2012 & 5.74 & 4.88 & 5.35 & 6.38 \\
2013 & 7.01 & 6.06 & 6.5 & 6.975 \\
2014 & 6.38 & 5.1 & 5.85 & 7.49 \\
2015 & 7.83 & 6.96 & 7.29 & 7.836 \\
2016 & 9.04 & 7.55 & 8.23 & 7.769 \\
2017 & 9.195 & 8.13 & & \\
\hline
\end{tabular}

Overall, there are a lot of positive impacts of tourism to a country, but the tourism also carries negative impacts which will be discussed in the next section.

\subsection{Negative}

It is important not only to look at the positive side of tourism, because it also carries negative impacts. As mentioned before, the improvement of infrastructure and facilities can happen too fast for the country to follow. There might not be time or money to make the improvements in time, which will lead to overcrowding and poor sanitation.

Along with the locals learning about other cultures, they might lose their own in the long run. Many countries try to adapt and make it comfortable for the tourists, leading them to lose their own traditions and native customs. In western culture, the Buddha image is often used as decoration, which means that when they come to Thailand, they want to have a Buddha figure as a souvenir. This goes against the religion and there are signs at most temples mentioning that the Buddha image is not for decoration, but most souvenir shops still sell them because they can make money.

Cities expand because of the demand of hotels which means that nature around the cities is ruined. Along with more transport and pollution, this leads to a negative effect on the ecological balance. More people also mean more use of natural resources, which will affect the country and local people in the long run.

When a country depends too much on tourism, they are in trouble when the tourists are not there. As mentioned previously, tourism is accountable for $15,1 \%$ of the total employment in Thailand, this is estimated to increase, but that might not be such a good idea because if the tourism decreases in the future, the unemployment will increase.
When talking about Thailand and their off-on season, this results in the insecurity amongst the employees at resorts and tourist places, because they will not know how long they will have their job.

The demand for products in the country increases, but the supply might not be able to meet the demand, which means an increase in the prices. [6]

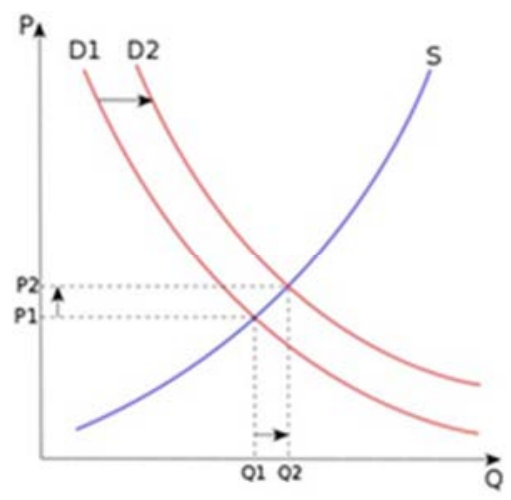

Figure 7. Demand and supply function.

The international hotels chains import products to meet their own standards, but with import taxes, the products will be overpriced, meaning that the locals cannot afford it, because their salaries have not increased along with the prices.

Pick-pocketing and scams are also a problem in Thailand, because some people associate tourists with easy money. This is also a result of the increased prices and non-changed salaries in the country.

When talking about imports, one can also talk about the tourism leakage. A report from 2011 estimated that $70 \%$ of all money spent by tourists actually ended up leaving Thailand.

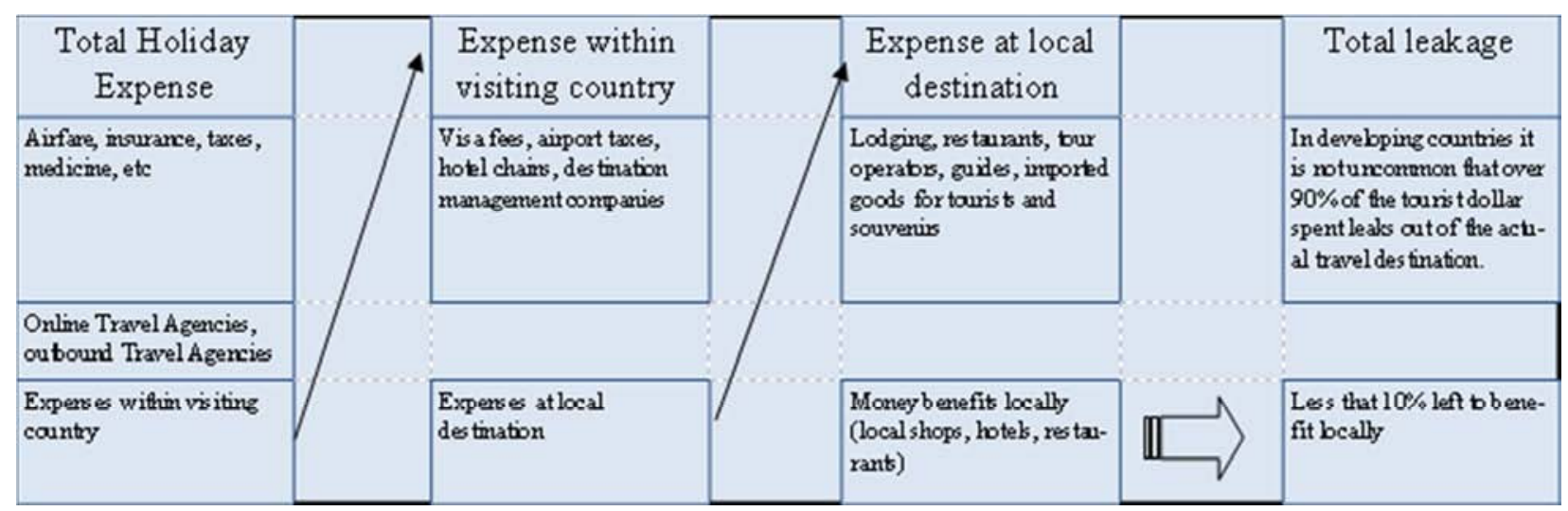

Figure 8. Tourism Leakage. 
The figure shows tourism leakage. First, a lot of the travel expenses are truly spent before the actual trip. This money goes to airlines, international travel agencies, medicine bought in home country, etc.

When coming to the country, there are often expenses such as visa fees, inbound travel agencies and transportation providers. This might benefit the local economy, but most hotel chains have airport shuttle services which most tourists have booked and paid for in advance.

At the destination, expenses for shopping, eating, activities, etc. will benefit the local economy if they are used outside the hotels and at the local stores, restaurants and travel agencies. If the country has a large gap between rich and poor, the money may never reach the poor, because they cannot provide products to international standards.

International hotel chains will more likely hire internationally trained employees instead of the local because they again have certain standards.

Leakage is what happens with many Chinese tourists, they spend money on Chinese airlines, hotels, travel agencies, etc. meaning that the money stays in China. The government's crackdowns on zero-dollar tours are their way of trying to prevent this. Another way the government is trying to minimize the leakage, is by requiring that tourists are in possession of at least $20.000 \mathrm{THB}$ or equivalent to that amount. This is a way to prevent tourists from working while visiting the country and to make sure the money is spent in Thailand and therefore staying in Thailand. [3, 14]

There are both positive and negative impacts of tourism, and even though tourists spend money in the country they are visiting, are these money actually staying in the country? With the increase of all-inclusive hotels and people making all the plans from their home country, less money stays in the country in the end.

The next section will look at the correlations between the different numbers and see if and how they affect each other.

\section{Discussion}

\subsection{The Roles of the Tourism Industry in the Thai Economy}

This section will focus on the numerical side of the impact of tourism industry on Thailand's economic growth by using some numbers range from 2012 to 2016 collected from the secondary source.

Economic Growth and GDP (Gross domestic product) are two measures used to indicate the economic condition of a country, the key difference between economic growth and GDP is that economic growth is the increase in the ability of an economy to produce goods and services over time whereas GDP is the monetary value of all goods and services produced in a period.

The implication is the association between tourism industry variables and the Gross Domestic Product (GDP) of Thailand over the last five years (from 2012 to 2016). In other words;

First it is needed to find the nature of the relationship and how strong it is between these two factors related to tourism industry affecting the Gross Domestic Product and thus the economic growth of Thailand (job opportunities and total contribution of tourism industry to employment in Thailand as well as internal consumption) and the number of tourist arrivals to Thailand during the period from 2012 to 2016, referring to tourist arrivals to Thailand as the independent variable. Employment and internal consumption will be the dependent variables.

Secondly to find the relationship between the contribution of tourism industry toward the Gross Domestic Product of Thailand and Thailand's GDP during the same period (from 2012 to 2016).

Finally to conclude with the relationship between the number of tourist arrivals to Thailand and the Gross Domestic Product of Thailand. In other word, to find how Thailand's GDP was related to tourism industry during the last 5 years and thus, so to make an assumption about the impact of tourism industry on Thai's economic growth. Referring to the number of tourist arrivals in Thailand as the independent variable, and the Gross Domestic Product of Thailand as the dependent variable.

This research used statistical package software to find the correlation between our variables, using the correlation analysis to find the nature of any existing relationship between the variables (tourism industry variables and Thai GDP).

Using Pearson's $r$ (Pearson correlation coefficient) to measure the strength of the relationship found between variables, the following assumptions were possible.

\subsection{The Power of Tourism and Travel}

Table 2. Thailand's GDP and Tourism variables.

\begin{tabular}{lllll}
\hline & Dependent & Dependent & Dependent & Dependent \\
\hline Year & $\begin{array}{l}\text { GDP of Thailand } \\
\text { (billion THB) }\end{array}$ & $\begin{array}{l}\text { Total contribution Tourism } \\
\text { to GDP (billion THB) }\end{array}$ & $\begin{array}{l}\text { * Internal travel and tourism } \\
\text { consumption (billion THB) }\end{array}$ & $\begin{array}{l}\text { Total contribution to } \\
\text { employment (million people) }\end{array}$ \\
\hline 2012 & $12,347.40$ & $2,014.25(16.35$ of GDP) & $1,757.80$ & 5.05 \\
2013 & $12,921.17$ & $2,287.04(17.7 \%$ of GDP) & $2,057.00$ & 5.60 \\
2014 & $13,203.75$ & $2,257.84(17.2 \%$ of GDP) & $1,910.80$ & 4.76 \\
2015 & $13,672.87$ & $2,638.86(19.3 \%$ of GDP) & $2,125.00$ & 5.41 \\
2016 & $14,360.63$ & $2,958.28(20.6 \%$ of GDP) & $2,305.20$ & 5.74 \\
\hline
\end{tabular}

$*$ GDP $\$ 1=34$ THB 


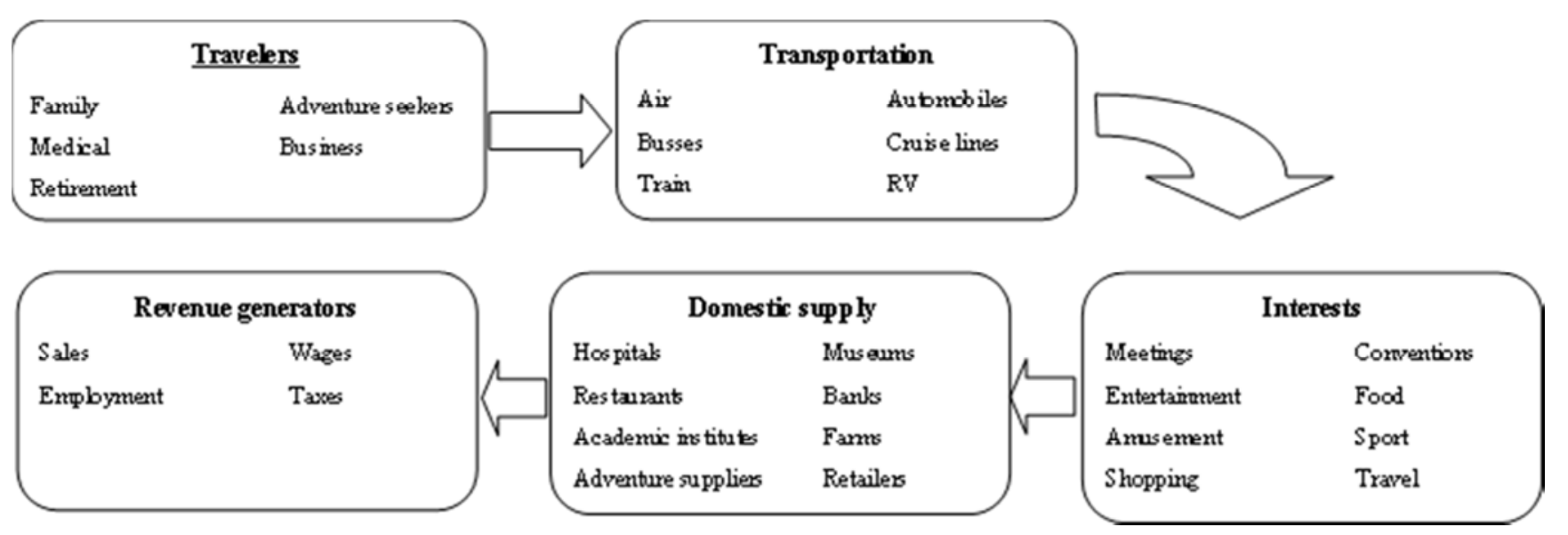

Figure 9. The Power of Tourism and Travel

The values of the variables collected are evaluated based on the prices of 2016 .

The values collected on US\$, was exchanged at the rate based on $\$ 1=34 \mathrm{THB}$

From the first glance, notice a decline in tourist arrivals in 2014 that was attributed to the political crisis in Thailand during "the first half of 2014," in which parts of Bangkok were paralyzed by street protests that aimed to topple the government of Prime Minister Yingluck Shinawatra. The protests, which occasionally turned violent, came to an end when the military staged a coup and declared nationwide martial law in May 2014. The military also imposed a10 pm -6 am curfew in Thailand for several weeks.

Table 3. Thailand GDP growth rate; Changes in employment ratio and tourist arrivals.

\begin{tabular}{lllll}
\hline Year & GDP Growth rate & $\begin{array}{l}\text { Changes in GDP } \\
\text { Growth rate }\end{array}$ & $\begin{array}{l}\text { Employment to } \\
\text { population ratio }\end{array}$ & $\begin{array}{l}\text { Changes in } \\
\text { employment ratio }\end{array}$ \\
\hline 2012 & 7.2 & $762.3 \%$ & 72.60 & $(-0.5 \%)$ \\
2013 & 2.7 & $(-62.28 \%)$ & 71.10 & $(-1.98 \%)$ \\
2014 & 0.9 & $(-66.51 \%)$ & 70.90 & $(-0.34 \%)$ \\
2015 & 2.9 & $221.41 \%$ & 70.90 & $(-0.02 \%)$ \\
2016 & 3.2 & $9.83 \%$ & 70.80 & $(-6.54 \%)$ \\
\hline
\end{tabular}

(Population aged 15 years and above)

The number of foreign tourists who visited Thailand in 2014 was down by $6.54 \%$ from the previous year, and so do the GDP growth rate of Thailand by a decrease of $66.51 \%$. This lead to the first sign of the level of the responsiveness of Thailand's GDP to a change in the number of tourist arrivals and how Thailand's GDP growth rate is elastic. The correlation table showing the relationship between tourism industry variables and the Gross Domestic Product of Thailand during the last 5 years.

Table 4. Correlation table - Tourism industry variables and Thailand GDP.

\begin{tabular}{|c|c|c|c|c|c|}
\hline & $\begin{array}{l}\text { GDP of Thailand } \\
\text { (billion THB) }\end{array}$ & $\begin{array}{l}\text { Total contribution } \\
\text { Tourism to GDP } \\
\text { (billion THB) }\end{array}$ & $\begin{array}{l}\text { Internal tourism } \\
\text { consumption } \\
\text { (billion THB) } \\
\end{array}$ & $\begin{array}{l}\text { Total contribution } \\
\text { to employment } \\
\text { (million people) } \\
\end{array}$ & $\begin{array}{l}\text { Tourist } \\
\text { arrivals }\end{array}$ \\
\hline GDP of Thailand (billion THB) & 1 & & & & \\
\hline Total contribution Tourism to GDP (billion THB) & $\begin{array}{l}\mathrm{r}=0.981528688 \\
\mathrm{P}=.0030\end{array}$ & 1 & & & \\
\hline Internal tourism consumption (billion THB) & 0.924441872 & 0.958164339 & 1 & & \\
\hline Total contribution to employment (million people) & 0.555875582 & 0.822972535 & 0.809044911 & 1 & \\
\hline
\end{tabular}

$r=$ Pearson's correlation coefficient

$\mathrm{p}=$ Significant level. Correlation is significant at 0.5 level 2 tailed

From the correlation table analysis (table 5) and the numbers provided in (figure 10) we conclude with the followings;

(1) From the economic viewpoint, table 3 indicates that; an increase in the number of tourist arrivals to Thailand increases the income of businesses like travel agencies, hotels, restaurants etc. and government (taxes). This would lead to a greater demand of labor and thus decreases the unemployment rate.

From the practical viewpoint, figure 12 shows a strong positive (direct) relationship between tourist arrivals in Thailand and total contribution to employment with the 
correlation coefficient $\mathrm{r}=0.758$.

(2) From the economic viewpoint, as demand for employment goes up, household and government income increase. As a result, the supply of goods and services goes up (leakage from exports; situation discussed in the previous section). Thus, with the increase in the number of tourist arrivals, the final income increases (income multiplier effect). This situation would lead to greater internal consumption.

From the practical viewpoint, table 5 shows a strong positive correlation between the number of tourist arrivals and the internal consumption with (P's) $r$ equal to 0.98 .
(3) The increase in demand and supply (goods and services) employment and consumption increases the contribution of tourism to GDP. This situation supported by the correlation analysis presented in table 5 which indicated that the total contribution of tourism to GDP is positively related to the number of tourist arrivals, with $r=0.98$, which is significant at $\mathrm{p}<.0014$

The line graph below shows the relationship between the number of tourist arrival and the total contribution of tourism to Thailand's GDP over the past five years.

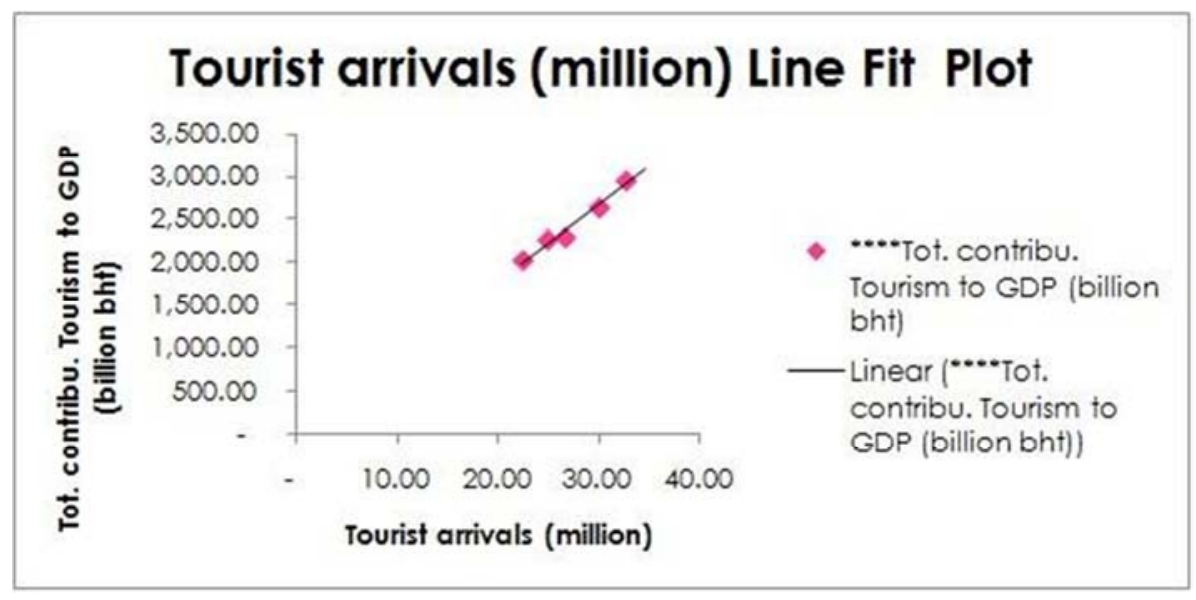

Figure 10. Tourist arrivals.

(4) Finally, table 3 shows that the increase in the total contribution of tourism industry toward GDP followed by an increase in the GDP of Thailand. This assumption was demonstrated in the correlation table analysis (table 5), which shows a very strong positive (direct) relationship between the total contribution of tourism industry toward GDP and Thailand's GDP with $\mathrm{r}=0.981$ significant at $\mathrm{P}<.0030$.

The line graph below shows the relationship between the total contributions of tourism to Thailand's GDP and the GDP of Thailand.

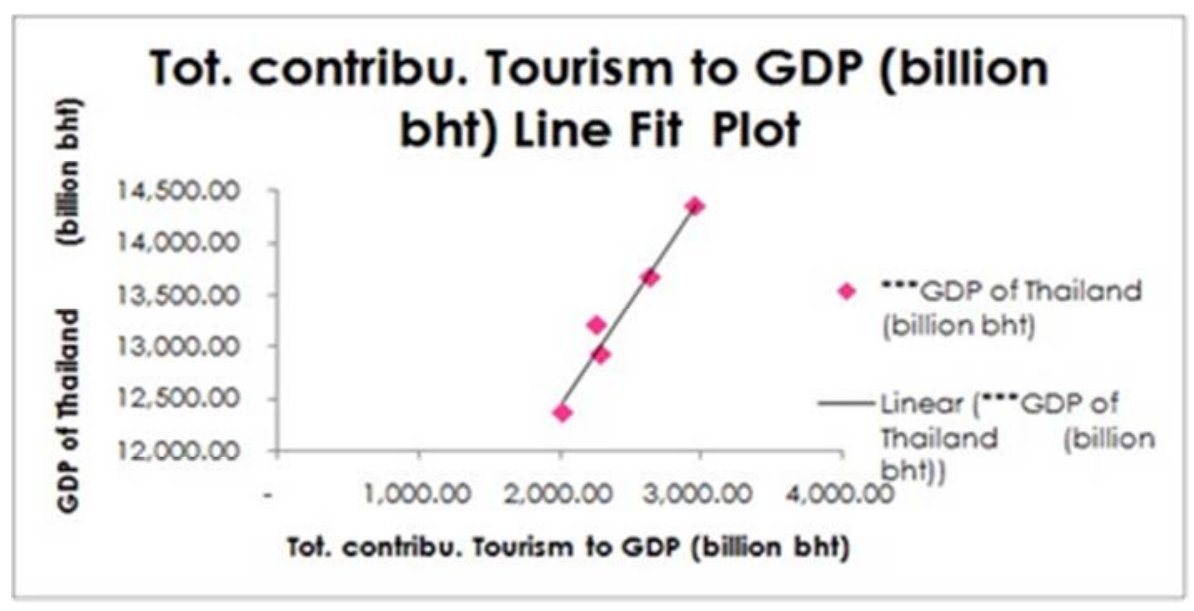

Figure 11. Total contributions Tourism to GDP.

At the end it can be concluded that there is a very strong direct association between the number of tourist arrivals in Thailand and the GDP of Thailand (as showed in the graph below) with $r=0.95$ and $p<.05$ thus, economically we can make assumptions about how Thailand's economic growth was related to tourism industry during the last 5 years.

In other words, it can be assumed that tourism industry in Thailand was considered as a main factor affecting the economic performance over the last 5 years. 


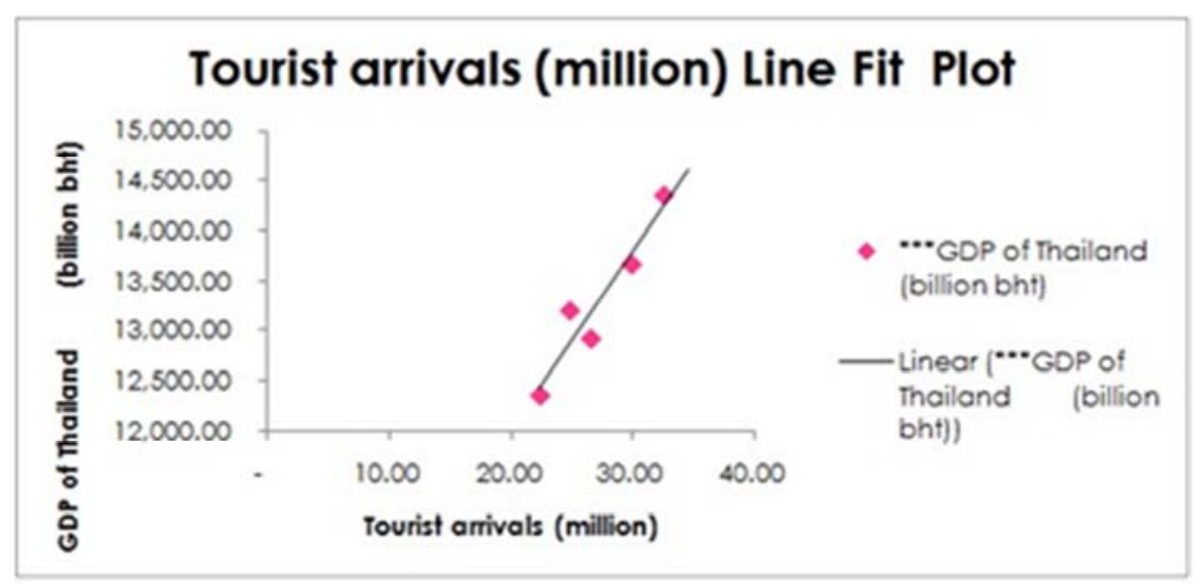

Figure 12. Tourist arrivals.

\subsection{Tourism and Industry Variables}

The correlation table (table 5) shows a very strong positive relationship between tourist arrivals to Thailand and internal tourism consumption with $\mathrm{r}=0.982$ during the last 5 years. Also, a very strong positive relationship between tourist arrivals to Thailand and the total contribution to employment with $\mathrm{r}=0.988$ during the past 5 years.

\subsection{Price Ceilings and Price Floors}

\subsubsection{Price Ceiling for Chinese Tours}

An example of price ceiling in tourism industry is that agreement reached in 2015 by Thai tour agents to set a maximum price for optional tours for Chinese visitors at 600 Yuan $(3,175 \mathrm{THB})$ per head. In recent years, Chinese tourists have been lured to buy cheap package holidays to Thailand. When here, if they did not buy optional tours, they would be abandoned or taken to places where they were forced to buy expensive goods.

\subsubsection{Price Floor (Crackdown on Zero-Dollar)}

The crackdown on "zero-dollar" Chinese tourists (discussed in previous section) is a measure launched in September 2016 with initiative, shutting down three zerodollar tour companies and impounding 2,150 tour buses. The campaign targeted Chinese tour companies offering cheap tour packages to largely first-time travelers that resulted in more pain than pleasure for both the tourists and the Thai businesses catering to them.

\subsubsection{Tax Break for Domestic Travel Expenses (Holiday Tax Break)}

"According to the Tourism Authority of Thailand TAT's initial proposal, tourists who spent during the final quarter of this year (2017) would be allowed to claim a personal income tax deduction of 10,000-50,000 baht, depending on the area visited" Travel expenses paid for domestic accommodation such as those paid to hotels, restaurants and travel agencies can be used for personal income tax deductions not exceeding 15,000 baht in order to boost weak domestic tourism during the year's end under this plan.

\section{Conclusion}

The economic situation in Thailand in the year 2017 was fragile but at the same time there was still some positive growth. The political situations both in Thailand and in other part of the world are strong factors that affect the downs in the GDP and economy in the country. Factors such as recovery of domestic household spending and increase in government spending are among the factors that contribute to the ups in the economy.

Thai government and private sectors in Thailand have been pro-active in boosting of the Thai tourism via several promotional campaigns. As a result, the travel and tourism sector has grown to become one of the country's most productive and sustainable industries. Comparing to Sex, Adventure, and Retirement Tourism, Medical Tourism is the largest growing and leading sector within Thailand's extensive tourism. Foreigners coming to Thailand seek treatment for everything from open-heart surgery to gender reassignment so this have made Thailand's private hospitals the world's leading destination for medical tourism, attracting an estimated 2.81 million patients in 2015, up 10.2 percent.

In determining the country's long-term profitability according to the Porter's Five Competitive Forces; threat of entrants, bargaining power of buyers, bargaining power of suppliers, threat of substitution and rivalry among existing competitors determine the long-run profitability of the industry, the analysis proved that the country has promising growth in the long-run. The high industry growth rate attracts more investors and many international hotel operators is expanding their business in major tourist attraction cities in Thailand. Being one of the top destinations in Asia with affordable tour packages and medical treatments, the threat of substitutes is low and this shift will remain with the government's new policies and campaigns. In addition, Thai government is now working actively on Thailand Tourism 4.0 initiative. This move aims to strategically improve the long-term sustainability of Thailand's tourism market. This 
dynamic strategy gives generous incentives to investors and travelers which will help increase the competitiveness of Thailand tourism in competing with other countries in the region as well as sustain the industry in long run. Despite some political problems which lead to the decrease in the number of tourist arrival, it only affected Thai tourism industry for 2-3 months before growing again.

There are several impacts from tourism, both positive and negative. For the negative part, tourists coming to Thailand may disturb local culture as the local people may copy the lifestyles of tourists through the demonstration effect and the result could be loss of native customs and traditions. However, more tourists mean more money circulates in the country which has a positive effect for the Thai economy. However, not all business in Thailand, especially small local business, will benefit from the growth in the industry. This could result in the bigger economic inequality between rich and poor people which may lead to the increase in crimes, pick- pocketing and scams.

Tourist arrivals in Thailand have a strong positive relationship with Thailand's economic performance over the period from 2012 to 2016 as the practical part demonstrated. The assumption is, with the increase in the number of tourist arrivals, the total consumption increases, and this leads to greater demand for employment, then the final income goes up (income multiplier effect) which increases again the internal consumption. As the consumption increases, there would be more demand and supply for labor, and this situation increases the contribution of tourism industry toward Thailand's gross domestic product and thus, a good economic performance of the country.

However, there are some limitations in the practical part of this paper. First and again, the GDP of a country is a broad area with too many affecting factors in different sectors this paper discussed only on the affecting factors that arise from tourism industry (employment and consumption). Secondly, this part is focusing only on the collected data ranged from 2012 to 2016, so the findings from the correlation analysis are only about that precise period and at the end, concluding with assumptions based on the strong associations found between tourism industry variables and Thailand's GDP.

Finally, a good connectivity in the urban, rural, and touristic sites areas is essential for tourism industry and a country's economic growth, and Thailand still need to develop more transport infrastructures in order to facilitate Thailand tourism industry.

\section{References}

[1] Lind, D. A., Marchal, W. G., Wathen, S. A. (2011). Statistical Techniques in Business and Economics. McGraw Hill Education

[2] Amazing Thailand Tourism Year 2018. (September 2017). Retrieved from http://thailand.prd.go.th/ewt news.php?nid $=5649 \&$ filename $=\mathrm{i}$ ndex

[3] Economic Impact of Tourism in Thailand. (September 2017). Retrieved from

https://tourthaitour.wordpress.com/pages/economic-impact-oftourism-in-thailand/

[4] GDP in Thailand. (September 2017). Retrieved from http://www.theglobaleconomy.com/Thailand/data_gdp_curren t_local_currency/

[5] Healthy outlook for Thai medical tourism demand. (August 2017). Retrieved from

https://www.thenational.ae/business/travel-and-

tourism/healthy-outlook-for-thai-medical- tourism-demand1.153848

[6] Impacts of Tourism: Phuket, Thailand. (September 2017). Retrieved from https://www.patana.ac.th/Secondary/Geography/IB/Globalisati on/Impacts\%20of\%20 Tourism\%20Phuket\%20Thailand.htm

[7] SCB Outlook Quarter 1/2017. (August 2017) Retrieved from https://www.scbeic.com/en/detail/file/product/3140/emidpoev y0/Outlook_EN_Q1_2017.p df

[8] Shifts in medical tourism. (September 2017). Retrieved from http://www.ttrweekly.com/site/2017/08/shifts-in-medicaltourism/

[9] TAT's marketing plan 2018 to heighten Thailand as a preferred destination. (September 2017). Retrieved from http://www.tatnews.org/tats-marketing-plan-2018-to-heightenthailand-as- a-preferred-destination/

[10] Thailand: Adventure Travel in Thailand. (September 2017). Retrieved from https://www.tripadvisor.com/Travel-g293915c16433/Thailand:Adventure.Travel.In.Thailand.html

[11] Thailand tourism healthy. (September 2017). Retrieved from https://www.bangkokpost.com/travel/tourists-andexpats/1319947/thailand-tourism-healthy Thailand Tourism Statistics. (September 2017) Retrieved from https://knoema.com

[12] Travel and Tourism Economic Impact 2017 Thailand. (September 2017). Retrieved from https://www.wttc.org//media/files/reports/economic-impact-research/countries2017/thailand2017.pdf

[13] The perks of retirement in Thailand and the Philippines. (September 2017). Retrieved from https://money.usnews.com/money/blogs/onretirement/2014/09/30/the-perks-of-retirement- in-thailandand-the-philippines

[14] Tourism growth in Thailand gets back on track. (September 2017). Retrieved from https://www.oxfordbusinessgroup.com/overview/resilient-risereturn-strong-growth-visitor- numbers-after-modest-decline

[15] Tourism leakage: Does your money contribute locally? (October 2017). Retrieved from http://beachmeter.com/tourism-leakage-does-your-moneycontribute-locally/

[16] Tourism statistics Thailand 2000. (September 2017). Retrieved from http://www.thaiwebsites.com/tourism.asp. 